$930(1965)$.

3. Eveleigh, V. W., "Adaptive Control and Optimization Techniques," McGraw-Hill, New York (1968).

4. Gibson, John E., "Nonlinear Automatic Control," McGrawHill, New York (1963).

5. Ho, K. W., Trans. ISA (Instr. Soc. Am.), 3, 184 (1964).

6. Kermode, Richard I. and W. F. Stevens, Can. J. Chem. Eng., 39, 81 (1961).

7. Lance, G. N., "Numerical Methods for High-Speed Computers," Iliffe \& Sons, London, England (1960).

8. LaSalle, J., and S. Lefschetz, "Stability by Lyapunov's Direct Method," Academic Press, New York (1961).

9. Mishkin, Eli, and L. Braun, Jr., "Adaptive Control Systems," McGraw-Hill, New York (1961).
10. Newton, G. C., Jr., L. A. Gould, and J. E. Kaiser, "Analytical Design of Linear Feedback Controls," John Wiley \& Sons, Inc., New York (1957).

11. Parks, Patrick C., IEEE (Inst. Elec. Electron. Engrs.) Trans., AC-11, No. 3, 362 (1966).

12. Schultz, W. C., and V. C. Rideout, IRE (Inst. Radio Engrs.) Trans. AC-6, 22 (1961).

13. Stevens, William F., and L. A. Wanninger, Jr., Can. J. Chem. Eng., 44, 158 (1966).

14. Wilde, D. J., "Optimum Seeking Methods," Prentice-Hall, Inc., Englewood Cliffs, N. J. (1964).

Manuscript received June 17, 1968; revision received May 13, 1969; paper accepted May 29, 1969.

\title{
Separation of Nitrogen
via Periodic Adsorption
}

\author{
PHILIP H. TURNOCK and ROBERT H. KADLEC
}

University of Michigan, Ann Arbor, Michigon

\begin{abstract}
The periodic process utilizes a rapid pressure swing cycle in an adsorbent bed to effect the separation of gas mixtures. During the first portion of a cycle the compressed gas mixture flows into the adsorbent-filled column. Next, while the feed gas is restrained, an exhaust orifice is opened at the feed end of the column providing depressurization. The product stream is enriched in the component exhibiting the lowest coefficient of adsorption.

A mathematical model based upon the assumption of instantaneous equilibrium between the gas phase and the adsorbed gas was formulated and solved to simulate the periodic, adsorption process. The measured nitrogen content of the product gas stream was found to correlote with the ratio of the product gas rate to the feed gas rote.

At $24^{\circ} \mathrm{C}$. the calculated pressure response, feed gas flow rate, and product gas composition correspond favorably with related experimental measurements for all values of the feed gas pressure, cycling frequency, and product gas flow rate within the ranges investigated.
\end{abstract}

Several unit operations have been studied under controlled cyclic operation since the principle was first reported by Cannon (I). Basically, these pulsed operations utilize repetitive parameter changes applied so rapidly that the system behavior remains transient in a cyclic steady state manner. Controlled cyclic operation has produced significant throughput increases and improved efficiencies for processes such as absorption, extraction, and distillation (2). In addition, Wilhelm (3) successfully demonstrated a dynamic adsorption process for separating fluid mixtures. The process, termed parametric pumping, relies upon an axial thermal gradient induced along a fixed adsorbent bed through which the fluid flows in repeatedly reversed directions.

The dynamic adsorption process to be discussed here differs from parametric pumping in that pressure rather than temperature provides the driving force for the separation. The periodic adsorption process employs a very rapid pressure swing cycle. The compressed feed gas mixture flows into an adsorbent-filled pipe, thereby pressurizing the column. Next, while the feed gas is restrained, an exhaust orifice is opened at the feed end of the column providing depressurization. These feed and exhaust periods of a cycle are of such brief duration ( 0.05 to 0.4 cycles $/ \mathrm{sec}$.)

P. H. Turnock is with Union Carbide Corporation, Tarrytown, New York.

that a product stream may be withdrawn continuously from the opposite end of the pipe. The product stream is enriched in the component exhibiting the lowest coeffcient of adsorption.

The objective of this study was to attain a better understanding of the mechanism and behavior of the periodic adsorption process. The practicality of the selected nitrogen-methane feed gas mixture was dictated more by the availability of basic adsorption data (4) for such mixtures than by their appreciable natural and commercial occurrence.

Many parameters affect the cyclic separation of the nitrogen-methane mixtures. Of these only the column configuration and the minimum exhaust pressure have remained invariant throughout this investigation. However, the feed gas composition, the type and size of molecular sieve, and the percent feed time per cycle were established at suitable values by preliminary experimentation, and will remain fixed for this discussion. For most experiments, the column contained 42-60 mesh particles of type $5 \mathrm{~A}$ Molecular Sieve. A nitrogen-methane mixture containing 28.6 mole \% nitrogen was fed to the column during $50 \%$ of the cycle period. The effects of processing temperature, cycling frequency, feed gas pressure, and product gas flow rate are illustrated and discussed. The experimental results are compared with those predicted by a mathematical model postulating instantaneous equilibrium between the bulk gas and adsorbed gas. 


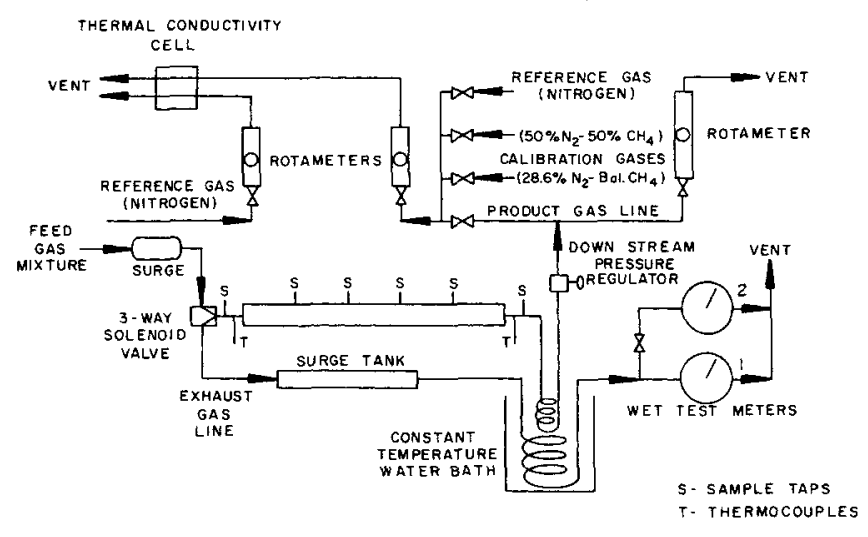

Fig. 1. Schematic diagram of the separation apparatus.

\section{APPARATUS}

The experimental and mathematical results for the periodic process relate to a 5 - $\mathrm{ft}$. long, $3 / 4$-in. diam. pipe packed with 42-60 mesh particles of Linde Type 5A Molecular Sieve. The processing scheme is illustrated schematically in Figure 1. The nitrogen-methane mixture fed to the periodic process is pressure regulated at the gas cylinder. A three-way solenoid valve controls the feed and exhaust cycling. Gas is fed to the column when the solenoid valve coil is electrically activated. When the coil is deactivated, the feed gas flow ceases while the column exhausts to atmospheric pressure. The solenoid coil is controlled by the square wave output of a function generator. The process cycling frequency control is conveniently set with the function generator.

The exhaust gas, exiting from the feed end of the column, passes through a wet test meter. Metering of the exhaust stream and the product stream furnishes the overall material balance for the separation process. The product line pressure regulator provides complete damping of the attenuated pressure pulsation of the product gas so that rotameters may be used to indicate the flow rates. The flow rates are regulated by needle valves immediately preceding the rotameters. The sample gas flow, one of the two parallel product streams, is maintained at a constant rotameter setting. This small fraction of the overall product stream flows through the sample side of a calibrated thermal conductivity cell to afford continuous product gas analysis. Further measurements of the system behavior are facilitated by the placement of quick-connect couplings at $1-\mathrm{ft}$. intervals along the pipe. These taps furnish access for both gas sampling and pressure response measurements.

\section{PROCEDURE}

An adsorbent bed of molecular sieve was prepared from 1/16 in. diam. pellets, crushed and classified on Tyler standard screens. The molecular sieve particles were added to the $3 / 4$-in. diam. pipe until the material remained flush with the top of the column, even after prolonged vibration of the packed bed. The bed was then mounted at an incline of about $35 \mathrm{deg}$. This upward slope of the column eliminated the possibility of a void channel along the top of the bed.

During the preparation of the adsorbent bed some moisture from the air inevitably contaminated the molecular sieve. Evacuation and purge gas stripping were utilized to remove this adsorbed moisture. The molecular sieve bed was replaced whenever attrition and compacting of the molecular sieve bed reduced the permeability below a level of 10 darcys. The average permeabilities over $1-\mathrm{ft}$. intervals of the bed were measured before each experiment. A nitrogen purge through the bed facilitated the permeability measurements and provided a uniform initial composition along the column. The adsorbent bed was characterized by the average permeabilities, average porosity, particle size, and total weight of molecular sieve for each experiment.

The temperature, feed gas pressure, product flow rate, cycling frequency, and percent feed time per cycle were controlled during an experiment. The exhaust gas rate, product gas rate, product composition, and pressure response were measured during the experimental run. In some instances the compositions of gas samples from along the bed were also measured. The time required for attainment of cyclic steady state operation and for subsequent experimental measurements ranged from 0.5 to $1 \mathrm{hr}$. per experiment. The flow conditions reached cyclic steady state within several minutes, while the product gas composition required up to $0.5 \mathrm{hr}$. to reach a uniform value.

\section{THE MATHEMATICAL MODEL}

The following observations by Lederman (4) for the adsorption of nitrogen-methane mixtures on a molecular sieve provide a basis for an equilibrium model of the periodic, separation process:

1. The total equilibrium amount adsorbed is relatively independent of composition and may be well represented by the Freundlich relationship

$$
N=k p^{1 / n}
$$

2. For single-component adsorption from the gas mixture, the use of the relative volatility $\alpha$ in conjunction with the total loading yields sufficiently accurate predictions, where

$$
\alpha=(y / z) /[(1-y) /(1-z)]
$$

Further assumptions incorporated in the model are

3. Ideal gas behavior

4. Darcy's law characterization of the molar gas flow rate through the packed bed

$$
q_{m}=\frac{T_{a}}{T} \frac{p}{p_{a}} \frac{K A}{\mu} \frac{1}{V_{m}}\left[-\frac{\partial p}{\partial l}\right]
$$

5. Attainment of instantaneous equilibrium between the gas phase and the adsorbed gas

6. Plug-flow conditions.

The postulation of instantaneous equilibrium eliminates rate considerations from the mathematical model. The basis for this assumption is theoretical, in the sense that it leads to a tractable model. It will be demonstrated, in the Results section, that the model thus produced gives reasonable results. Hence overall and single-component material balances will produce two partial differential equations, which, when solved with suitable boundary conditions, will characterize the cyclic separation process. Since the total equilibrium amount adsorbed is independent of composition, the overall material balance may be formulated and solved apart from the single-component balance. The resulting second-order, nonlinear, partial differential equation may be written in the following dimensionless form:

$$
\frac{\partial^{2} P(X, \theta)}{\partial X^{2}}=F(P) \frac{\partial P(X, \theta)}{\partial \theta}
$$

where

$$
\begin{aligned}
F(P)=\frac{T_{\mu} V_{m} L^{2}}{T_{a} K A \lambda}\left[\frac{A \emptyset}{R T} \frac{1}{P^{1 / 2}}\right. \\
\left.+\frac{k W}{n L} p_{a}^{(1 / n-1)} \frac{1}{P^{(1-1 / 2 n)}}\right] \\
P=P(X, \theta)=[p(X, \theta)]^{2 / p_{a}^{2}} \\
X=l / L \\
\theta=t / \lambda
\end{aligned}
$$

The dimensionless boundary values associated with Equation (4) are (for $0<\theta \leqslant 1$ ) 


$$
\begin{gathered}
P(0, \theta)=\left\{\begin{aligned}
p_{f}^{2} / p_{a}^{2}, & 0<\theta \leq 1 / 2 \\
1, & 1 / 2<\theta \leq 1
\end{aligned}\right. \\
\frac{K A T_{a} p_{a}}{2 V_{m \mu} L T}\left[-\frac{\partial P(X, \theta)}{\partial X}\right]_{\mathrm{X}=1}=C Q_{p}
\end{gathered}
$$

MATHEMATICAL MODELING PARAMETERS
PROCESS VARIABLES
CYCLING FREQUENCY, $f$
FEED GAS PRESSURE, Pf
PRODUCT GAS FLOW RATE, Op
TEMPERATURE, $T$
AOSORPTION EQUILIBRIUM CONSTANTS
FREUNOLICH CONSTANTS, $K$ AND $n$
RELATIVE VOLATILITY, $\propto$
GAS PROPERTIES
AVERAGE VISCOSITY FOR MIXTURE,
FEED GAS COMPOSITION, Y $f$
SYSTEM SPECIFICATIONS
COLUMN DIMENSIONS, A AND L
PRODUCT LINE VOLUME, $V$
MOLECULAR SIEVE WEIGHT, W
POROSITY OF PACKED BED, $\varnothing$
PERMEABILITY OF PACKED BEO, $K$

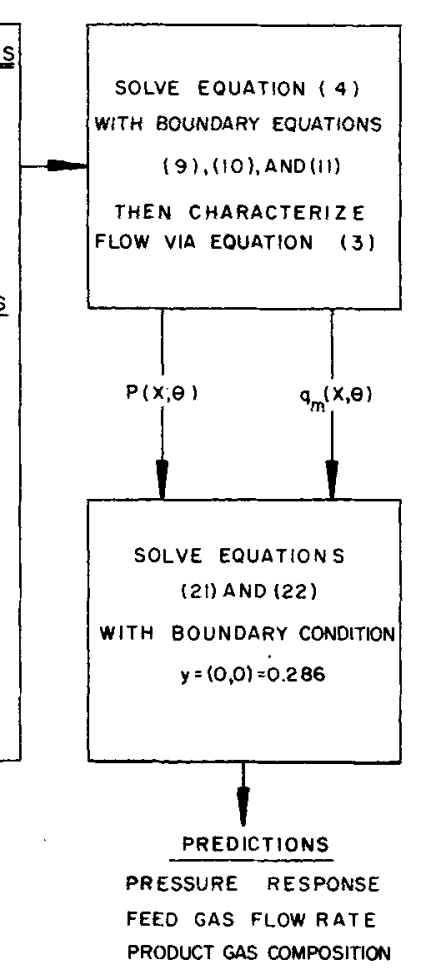

Fig. 2. Illustration of calculative procedure.

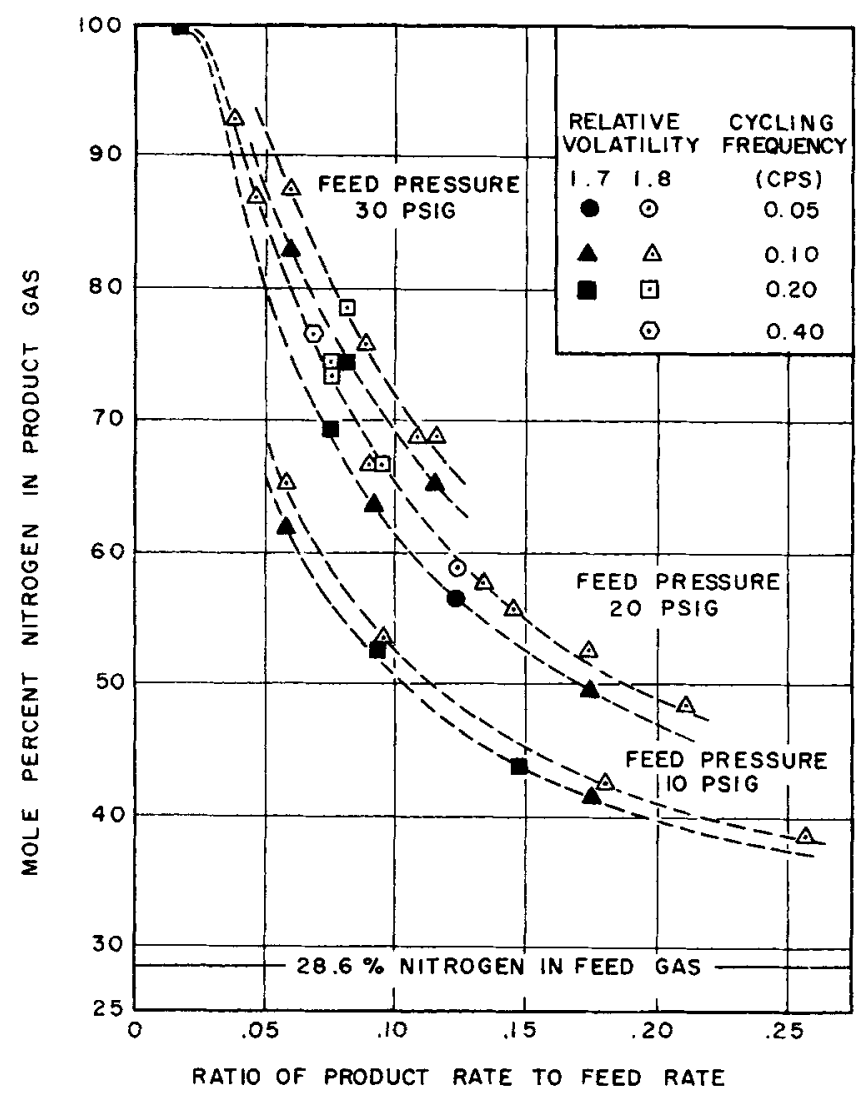

Fig. 3. Predicted product gas composition for vorious flow conditions ot $25^{\circ} \mathrm{C}$.

$$
+\left[\frac{V p_{a}}{2 R T_{a} \lambda P(1, \theta)^{t / 2}}\right] \frac{\partial P(1, \theta)}{\partial \theta}
$$

The time-boundary conditions are (for $0<X \leq 1$ )

$P(X, 0)$ for $i^{\text {th }}$ cycle $=P(X, 1)$ for $(i-1)^{\text {th }}$ cycle

$$
\text { with } P(X, 0) \text { for } 1^{\text {st }} \text { cycle }=1.0
$$

The cyclic steady state solution of Equation (4) utilizing the related boundary condition:, (9) to (11), is attained when the pressure distributions at the beginning and end of a cycle are identical.

Subsequent to the pressure and flow characterization of the cyclic separation process, a nitrogen balance may be written. The dimensionless, first-order, nonlinear, partial differential equation presented below is such a balance, and includes the terms $P(X, \theta)$ and $q_{m}(X, \theta)$ which must be attained through the solution of Equation (4):

$q_{m}(X, \theta) \frac{\partial y(X, \theta)}{\partial X}+f(X, \theta) \frac{\partial y(X, \theta)}{\partial \theta}$

where

$$
+h(X, \theta) y(X, \theta)=0
$$

$$
\begin{aligned}
& f(X, \theta)= \frac{1}{\lambda}\left[\frac{A L \emptyset P(X, \theta)^{1 / 2} p_{a}}{R T}\right. \\
&\left.\quad+\frac{p_{a}^{1 / n} P(X, \theta)^{1 / 2 n} W k_{\alpha}}{[\alpha-(\alpha-1) y(X, \theta)]^{2}}\right] \\
& h(X, \theta)= \\
&+\frac{p_{a}^{1 / n} P(X, \theta)^{(1 / 2 n-1)} W k}{2 \lambda n} \\
& {\left[\frac{1}{\alpha-(\alpha-1) y(X, \theta)}-1\right] \frac{\partial P(X, \theta)}{\partial \theta} }
\end{aligned}
$$

The boundary values associated with Equation (12) are (for $0<\theta \leq 1 / 2$ )

$$
\text { (for } 0 \leq X \leq 1 \text { ) }
$$

$$
y(0, \theta)=y_{f}
$$

$y(X, 0)$ for the $i^{\text {th }}$ cycle $=y(X, 1)$

$$
\begin{aligned}
& \text { for the }(i-1)^{\text {th }} \text { cycle with } \\
& \qquad y(X, 0)=1.0 \text { for the } 1^{\text {st }} \text { cycle }
\end{aligned}
$$

Due to the observation that the total equilibrium amount adsorbed is independent of composition, Equations (4) and (12) may be solved in succession to describe the pressure, flow, and separation characteristics of the cyclic process.

Linear, parabolic, partial differential equations have been extensively examined. In particular, references 5 and 6 discuss the procedures and stability oriteria for solution of such linear equations. The details presented in these references furnish a basis for solution of the nonlinear Equation (4) with the related boundary Equations (9) to (11). Equation (4) is not amenable to analytical solution. Linearization of Equation (4) by substituting an average, uniform value for the function $F(P)$ is not an effective simplification; the value of $F(P)$, defined by Equation (5), fluctuates considerably for simulation of the periodic process.

Equation (4) may be solved numerically through approximation of the derivatives by finite differences. Details of this procedure appear in reference 7. The computed, cyclic steady state pressure response for the process may then be applied to the computation of the gas flow rates. 
Table 1. Summary of Adsopption Data and Viscosities USED FOR Mathematical Simulation OF THE Crclic Process

\begin{tabular}{|c|c|c|c|c|}
\hline \multirow{2}{*}{$\begin{array}{l}\text { Temper- } \\
\text { ature } \\
T,{ }^{\circ} \mathrm{C} .\end{array}$} & \multicolumn{2}{|c|}{$\begin{array}{l}\text { Freundlich } \\
\text { relationship } \\
\text { constants }\end{array}$} & \multirow{2}{*}{$\begin{array}{c}\text { Relative } \\
\text { volatility } \\
\alpha \alpha\end{array}$} & \multirow{2}{*}{$\begin{array}{c}\text { Gas } \\
\text { viscosity, } \\
\text { cp. }\end{array}$} \\
\hline & $k$ & $n$ & & \\
\hline 25 & 1.0 & 4.0 & 1.7 to 1.9 & 0.0175 \\
\hline 0 & 1.6 & 5.0 & 1.7 to 1.9 & 0.0150 \\
\hline-78 & 3.6 & 14.6 & 2.0 to 2.2 & 0.0100 \\
\hline
\end{tabular}

Both the instantaneous flow rates $q_{m}(X, \theta)$ and the average flow rates $Q$ are required for subsequent gas separation calculations. Two procedures exist for determining the gas flow rates: The first would utilize Darcy's law, Equation (3), to convert the calculated pressures to flow information, while the second would employ gas accumulation estimates for prediction of flow rates. The latter method, ultimately found most suitable, was utilized in the computer calculations of the gas flow rates.

The gas separation may be predicted through solution of Equation (12) by the method of characteristics. This method presupposes that the solution of the nonlinear, first-order, partial differential equation can be obtained in the implicit form $\psi(X, \theta, y(X, \theta))=$ constant. Differentiating the implicit function with respect to the independent variables $X$ and $\theta$ yields

$$
\begin{aligned}
& \frac{d \psi}{d X}=\frac{\partial \psi}{\partial X}+\frac{\partial \psi}{\partial y} \frac{\partial y}{\partial X}=0 \\
& \frac{d \psi}{\partial \theta}=\frac{\partial \psi}{\partial \theta}+\frac{\partial \psi}{\partial y} \frac{\partial y}{\partial \theta}=0
\end{aligned}
$$

Insertion of the above expressions for the partial derivatives into Equation (12) produces

$$
\frac{q_{m}(X, \theta)}{f(X, \theta)} \frac{\partial \psi}{\partial X}+\frac{\partial \psi}{\partial \theta}-\frac{h(X, \theta) y(X, \theta)}{f(X, \theta)} \frac{\partial \psi}{\partial y(X, \theta)}=0
$$

At this stage in the mathematical development an arbitrary parameter $S$ is introduced; thus the implicit function $\psi[X, \theta, y(X, \theta)]$ may be restated as $\psi(X(S), \theta(S), y(S))$. Differentiation of the implicit function with respect to the independent variable $S$ yields

$$
\frac{d \psi}{d S}=\frac{\partial \psi}{d X} \frac{d X}{d S}+\frac{\partial \psi}{\partial \theta} \frac{d \theta}{d S}+\frac{\partial \psi}{\partial y} \frac{d y}{d S}
$$

Comparison of the terms in Equations (19) and (20) implies that $S=\theta$ and hence that

$$
\frac{d X}{d \theta}=\frac{q_{m}(X, \theta)}{f(X, \theta)}
$$

and

$$
\frac{d y}{d \theta}=-\frac{h(X, \theta)}{f(X, \theta)} y(X, \theta)
$$

Equations (21) and (22) represent the characteristic curves for the solution of Equation (12).

The cyclic steady state, pressure response, and flow rate predictions were used in conjunction with Equations (21) and (22) to compute the nitrogen enrichment in the product gas. The product gas composition was experimentally found to be time invariant. This is due to the effectiveness of the packed bed as a pulse-damping device. This observation means that computations were required along only one characteristic curve. Calculation of the product gas composition along with the flow rate and pressure response determinations completely characterized the operation of the periodic process.

The calculative procedure is summarized in Figure 2. Three distinct types of information may be predicted for the periodic process. The pressure response, feed gas flow rate, and product gas composition have been computed for a variety of operating conditions. The estimated average gas viscosity and applicable values of the equilibrium constants utilized in the process computations are presented in Table 1. The feed gas composition was set at 0.286 mole fraction nitrogen for the gas separation calculations. The computed product gas compositions at $25^{\circ} \mathrm{C}$. are portrayed in Figure 3 as a function of the ratio of the product gas rate to the feed gas rate. This ratio, termed the product cut for the separation process, does

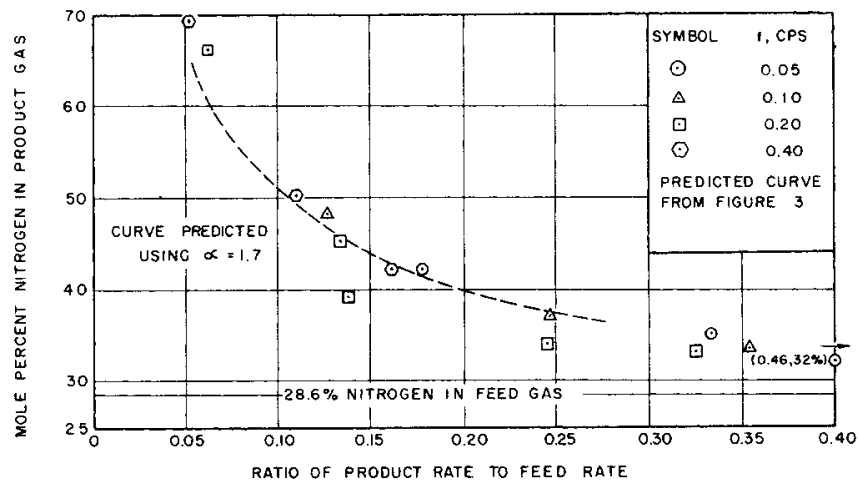

Fig. 4. Product gas compositions for various flow conditions at $10 \mathrm{lb} . / \mathrm{sq} . i n$. gauge feed gas pressure ond $24^{\circ} \mathrm{C}$. (42-60 mesh particles of Type 5A Molecular Sieve).

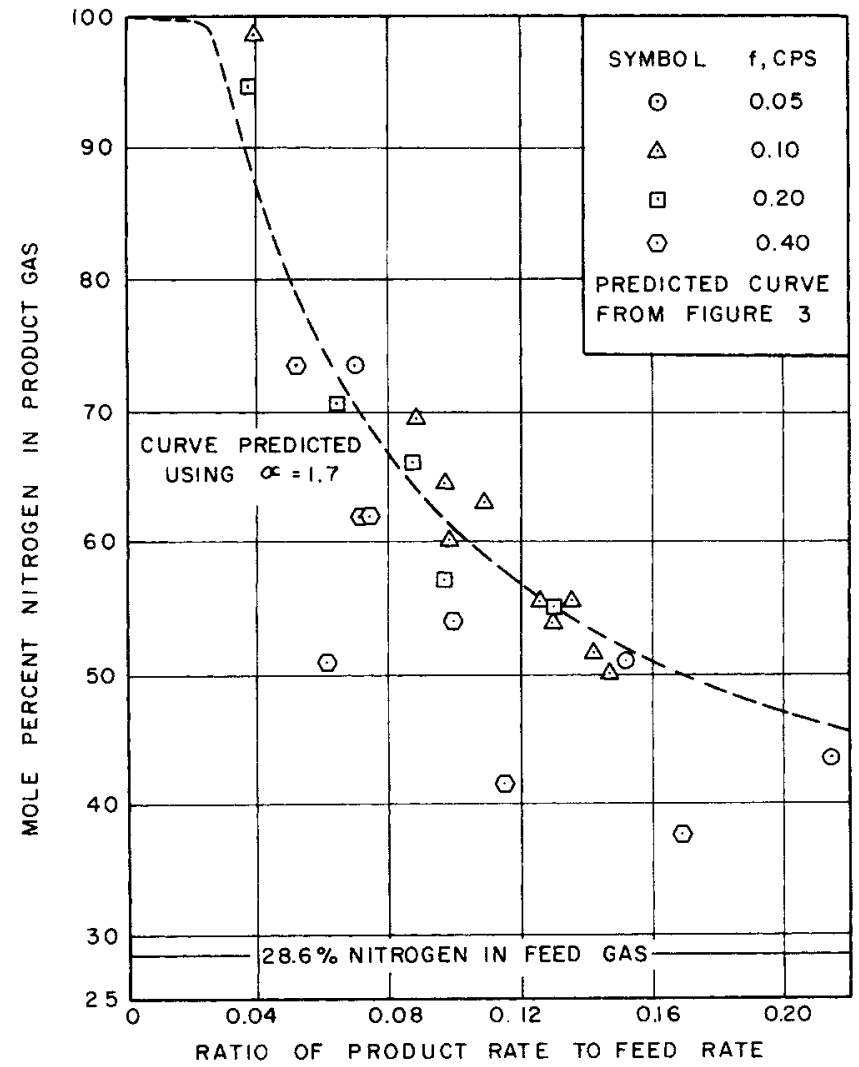

Fig. 5. Product gas compositions for various flow conditions at 20 Ib./sq.in. gauge feed gas pressure and at $24^{\circ} \mathrm{C}$. (42-60 mesh particles of Type 5A Molecular Sieve). 


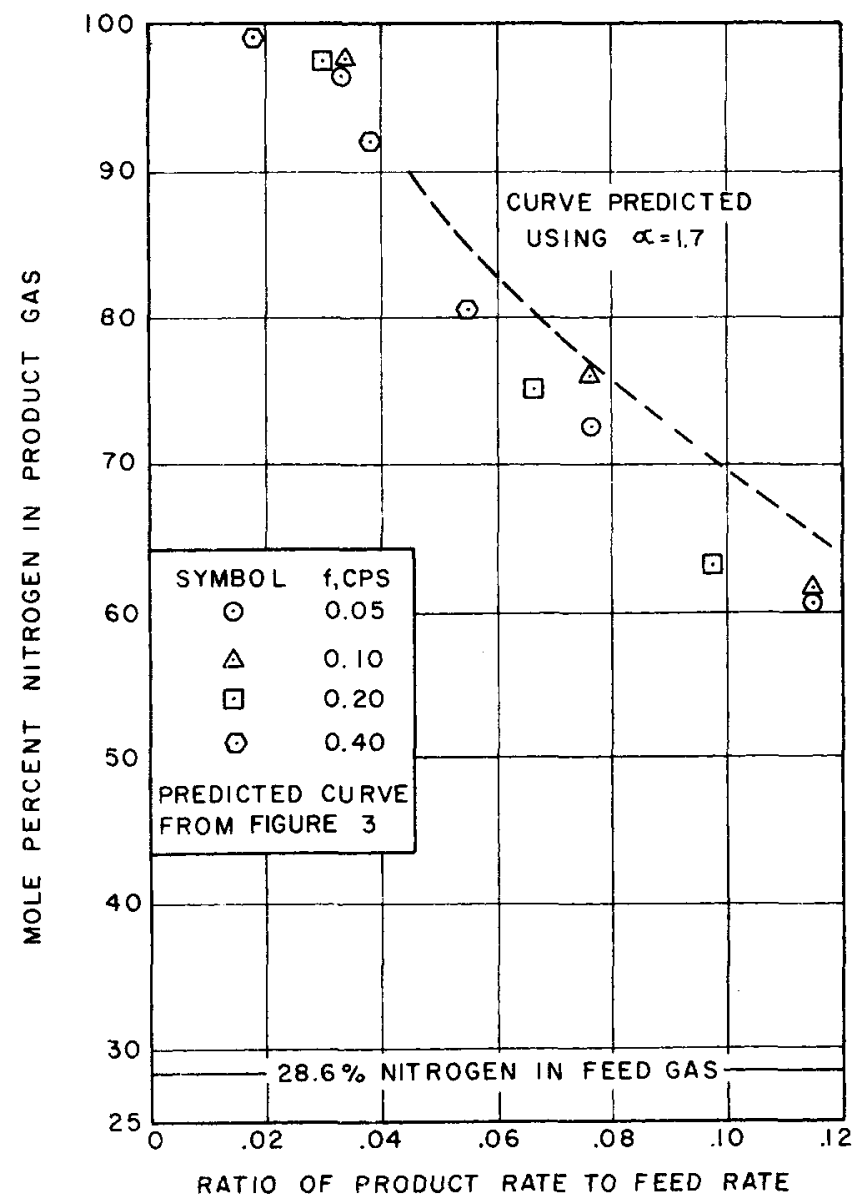

Fig. 6. Product gos compositions for various flow conditions at 30 Ib./sq.in. gauge feed gas pressure and at $24^{\circ} \mathrm{C}$. (42.60 mesh particles of Type 5 A Molecular Sieve).

not readily account for the capacity of the column. For a fixed product cut, the extent of nitrogen enrichment appears to be independent of the process cycling frequency and bed permeability over the limited ranges of the depicted variables. The curves from Figure 3 will be compared with similar correlations of the experimental results. Further mathematical modeling results are presented with the related experimental results.

\section{EXPERIMENTAL RESULTS}

A nitrogen-methane mixture containing 28.6 mole \% nitrogen was fed, during $50 \%$ of the cycle period, to a column packed with 42-60 mesh adsorbent. The selection of these fixed parameters was aided by several preliminary experiments conducted with other types and sizes of molecular sieve particles, various feed gas compositions, and different cyclic patterns. However only the effects of cycling frequency, feed gas pressure, product gas flow rate, and processing temperature are illustrated in the results which follow. The initial analyses pertain to the gas separation at ambient temperature. Where applicable, the experimental results will be interpreted in conjunction with the mathematically predicted results.

The distinction among the interrelated terms degree of separation, product cut, and column capacity is essential to proper analysis of the performance of the periodic process. The degree of separation relates to the amount of nitrogen enrichment in the product gas without regard for the amount of product gas obtained. One possible measure of the degree of separation is the difference between the nitrogen concentrations of the product gas and feed gas mixtures. The degree of separation is markedly influenced by the product cut for the periodic process, where the product cut is the ratio of the product gas flow rate to the feed gas flow rate. However, the product cut, being a ratio of gas flow rates, fails to account for the capacity of the adsorbent bed. The terminology column capacity or flow capacity will be used synonymously for the flow rate of the nitrogen-methane mixture to the column.

Analysis of the periodic process performance is complicated by the variation of bed permeability among experiments. Average permeability values over $1-\mathrm{ft}$. intervals of the column were measured between experiments in order to characterize the existing condition of the bed, but the permeability could not realistically be controlled. The permeability of the packed bed in the region near the feed end of the column generally decreased during cyclic processing of the gas mixture due to the compacting and attrition of the molecular sieve particles. This problem can be eliminated if a less friable adsorbent is used. Recent studies on spherical particles with high strength have shown no attrition or compacting after $100 \mathrm{hr}$. of operation.

Since the bed permeability in this work is a time-related variable which influences the separation characteristics of the periodic process, the experiments cannot be reproduced precisely. Moreover, the data are not amenable to statistical analyses, since the effects of the studied process variables are confounded with the permeability effect. Therefore, in order to illustrate concisely the effects of the process parameters, one must attemp to correlate the experimental data in a manner which obviates the effect of the permeability of the packed bed. Such a correlation exists between the degree of separation and the product cut. This correlation necessarily obscures the related column capacity and must be interpreted cautiously. The variation of the column capacity will be analyzed following the discussion of the degree of gas separation produced in the periodic process.

Figures 4 to 6 illustrate the relationship between the product gas purity and the product cut; the results demonstrate the degree of gas separation at $25^{\circ} \mathrm{C}$. for feed gas pressures of 10,20 , and $30 \mathrm{lb} . / \mathrm{sq} . \mathrm{in}$. gauge. The measured product gas concentration and the product cut are correlated independently of the bed permeability, cycling frequency, and product flow rate in the range of 19 to 30 darcys, 0.05 to 0.4 cycles/sec., and 0.5 to 2.0 std. cu.ft./ hr., respectively. The dashed lines through the experimental results in Figures 4 to 6 are established by means of the mathematical model. The computed results are

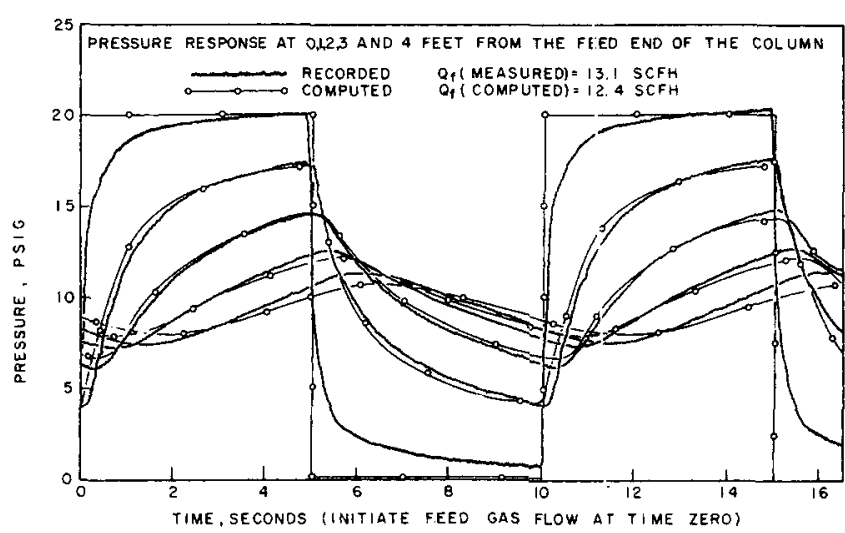

Fig. 7. Recorded and computed pressure curves for cyclic steady state operation at $24^{\circ} \mathrm{C}$. (conditions: 0 to $20 \mathrm{lb}$./sq.in. gouge; 0.1 cyele/sec., $Q_{p}=1.80$ std. cu.ft. $/ \mathrm{hr}$.). 


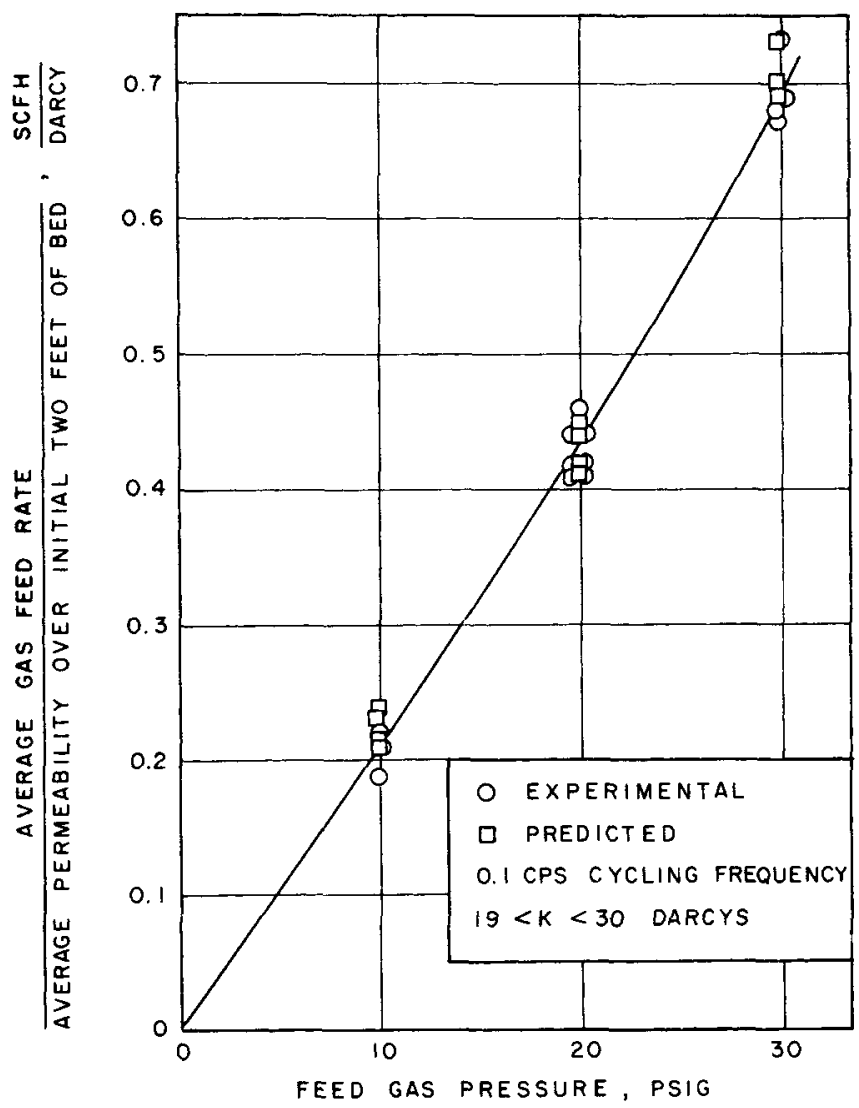

Fig. 8. Flow capacity of the column correlated with feed gas pressure.

based upon cycling frequencies of $0.05,0.1,0.2$, and 0.4 cycles/sec., bed permeabilities extending from 15 to 35 darcys, and product gas rated ranging from 0.2 to $2.0 \mathrm{std}$. cu.ft./hr.

The computed curves agree with the data with the exception of a few points. For these experiments the packed bed exhibited an abnormally low permeability near the column inlet. This high flow resistance coupled with the rapid cycling produced severely attenuated pressure waves along the column and correspondingly reduced gas separation.

The slight systematic deviation between the predicted and experimental results in Figure 6 cannot be accounted for either by the influence of bed permeability or by the experimental uncertainty of \pm 2 mole $\%$ nitrogen in the product gas. A possible explanation of this discrepancy at a $30-\mathrm{lb} . / \mathrm{sq}$.in. gauge feed gas pressure is the use of the assumption of instantaneous equilibrium in the derivation of the mathematical model. Attainment of the postulated adsorption equilibrium would become more difficult at higher feed gas pressures and higher gas flow rates.

Figure 7 illustrates a sample comparison between the computed and recorded pressure response curves. The close agreement between calculated and recorded pressure response curves further corroborates the reliability of the mathematical model. For this run the measured nitrogen content of the product gas was 55 mole $\%$, while that predicted through the process model was 54 mole $\%$. In addition, the predicted feed gas flow rate of $12.4 \mathrm{std}$. cu.ft./hr. compares favorably with the measured rate of 13.1 std. cu.ft./hr.

The flow capacity of the periodic process has been obscured throughout most of the previous discussion, since the degree of gas separation has been correlated as a function of the product cut. The method of presentation was

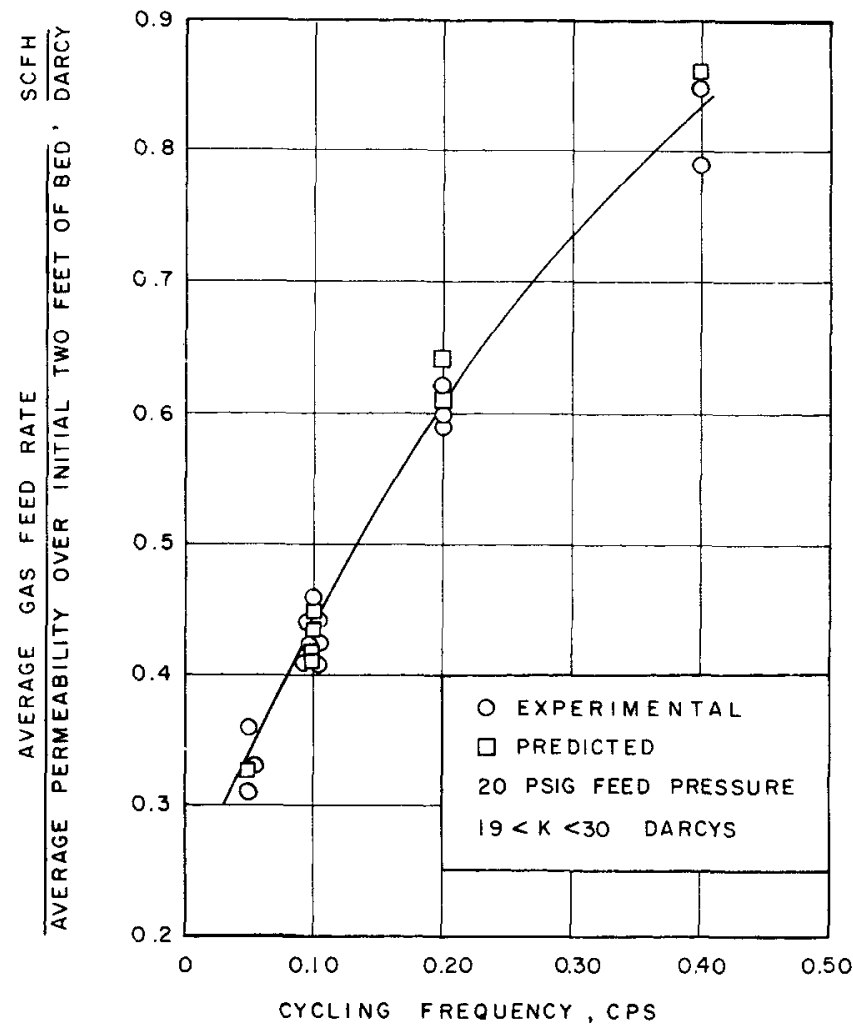

Fig. 9. Flow capacity of the column correlated with cycling frequency.

intended to circumvent the effect of variable bed permeability rather than demean the importance of process flow capacity. Clearly, establishment of the most efficient mode of operation of the periodic process requires optimization of some characterizing function which incorporates the degree of gas separation, product cut, and flow capacity. However, analysis of the experimental results through any such function is incongruous, since the existing alterations of bed permeability exert a significant influence upon the flow capacity, and hence the product cut for the periodic process.

The measured and predicted process flow rates may be normalized through division by the average permeability near the feed end of the column. The average permeability over the initial two feed of packed bed is one such normalizing factor. The resulting normalized flow parameters are presented in Figures 8 and 9 as a function of the feed gas pressure and cycling frequency, respectively. These data are indicative of the flow capacity of the process at $25^{\circ} \mathrm{C}$. The predicted and measured process performances are again in agreement. Figures 8 and 9 demonstrate the increased column capacity resulting from process operation at higher feed gas pressures and higher cycling frequencies. This enhanced flow capacity may be achieved without diminishing the nitrogen enrichment or recovery in the product stream.

In the low temperature experiments the feed gas pressure, cycling frequency, and product gas flow rate were altered only to the extent required to verify the correlations established for ambient temperature gas separation in a bed of 42-60 mesh particles. Figure 10 presents the measured product gas compositions for all experiments performed at $0^{\circ} \mathrm{C}$. in a bed of $42-60$ mesh particles of Type 5A Molecular Sieve. The lines drawn through the points illustrate the trends in the experimental data rather than any mathematical prediction. Reduction of the processing temperature to $0^{\circ} \mathrm{C}$. did not produce any signifi- 
cant deviations from the separation performance at $24^{\circ} \mathrm{C}$; the curves in Figure 10 correspond closely to those in Figures 4 to 6 . The effects of feed gas pressure, cycling frequency, and product flow rate for gas separation at $0^{\circ} \mathrm{C}$. were analogous to those at ambient temperature. The mathematical simulation at $0^{\circ} \mathrm{C}$. predicted a slightly greater product composition and feed gas flow rate than measured experimentally.

Figure 11 depicts the measured product gas composition as a function of the product cut for all experiments at $-77^{\circ} \mathrm{C}$. The line established by the correlated data lies considerably below the degree of separation exhibited by experiments at $24^{\circ}$ and $0^{\circ} \mathrm{C}$. The system specifications for the experimentation at $-77^{\circ} \mathrm{C}$. were analogous to those previously discussed. However, for a product cut of 0.05 and with a feed gas pressure of $20 \mathrm{lb} . / \mathrm{sq}$.in. gauge the measured nitrogen concentration of the product gas is 45 mole \% (Figure 11), while the predicted composition is 87.6 mole \% nitrogen. Thus the measured degree of gas separation at $-77^{\circ} \mathrm{C}$. is considerably below the prediction.

A plausible explanation exists for the divergence of the low temperature process performance from the low temperature prediction. The adsorption rate measurements of Habgood (8) exemplify the significant temperature dependence of the gas adsorption rate. For nitrogen-methane adsorption on activated Type 4A Molecular Sieve, Habgood's experiments revealed two important phenomena: First, reduction of the temperature to a level of $-77^{\circ} \mathrm{C}$. drastically retards the rate of gas adsorption; and second, for rate-controlled diffusion the nitrogen diffuses more rapidly than methane through the intracrystalline pores of the molecular sieve. Thus one might reasonably assume that at $-77^{\circ} \mathrm{C}$. the adsorption on a Type $5 \mathrm{~A}$ Molecular
Sieve is rate controlled by diffusion of the gas molecules into the cavities of the adsorbent crystals. Rate-controlled adsorption of the nitrogen-methane mixture in the periodic process would induce lower feed gas flow rates due to decreased accumulation of adsorbed gas within the column. Also, if the adsorption were rate controlled, methane would not be adsorbed preferentially to the extent possible under equilibrium conditions, and the degree of nitrogen enrichment in the periodic process would be correspondingly reduced. Hence postulation of rate-controlled adsorption at $-77^{\circ} \mathrm{C}$. will account for the observed discrepancies in process performance at low temperatures.

\section{RESULTS OF A SAMPLE DESIGN}

Suppose it were desired to enrich $10 \%$ of a nitrogenmethane stream of 10,000 std. cu.ft./hr. from $28.6 \%$ nitrogen to $60.0 \%$ nitrogen. This is to be accomplished using the adsorbant of the present study. C'se of Figures 3, 8, and 9 gives the following choice of design parameters: product cut, $10 \%$; pressure, $20 \mathrm{lb} . / \mathrm{sq} . \mathrm{in}$. gauge; cycling frequency, 0.4 cycles/sec.; on-time, $50 \%$.

To process the given amount of material, an adsorber consisting of 50 tubes $3 \mathrm{in}$. in diameter and $4 \mathrm{ft}$. long is required. Approximately $30 \mathrm{hp}$. would be required for compression if the incoming stream were atmospheric. Two percent of the compression energy would be used in the separation. Such a plant, installed and instrumented, would cost approximately $\$ 20,000$. The cost of the purification would be $\$ 1.00$ per thousand standard cubic feet of product. Consequently, one concludes that the equipment is feasible, but that processing costs are high if compression is required.

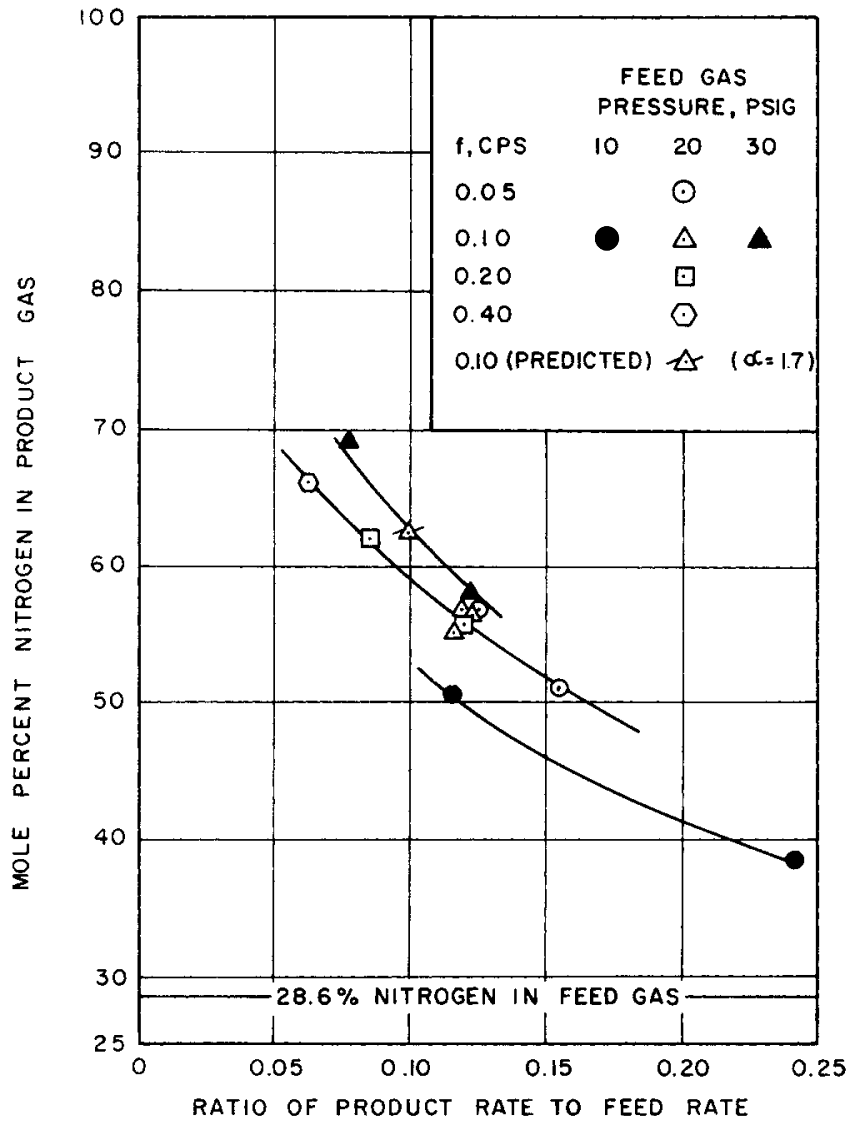

Fig. 10. Product gas compositions for various flow conditions of $0^{\circ} \mathrm{C}$. (42-60 mesh particles of Type 5A Molecular Sieve).

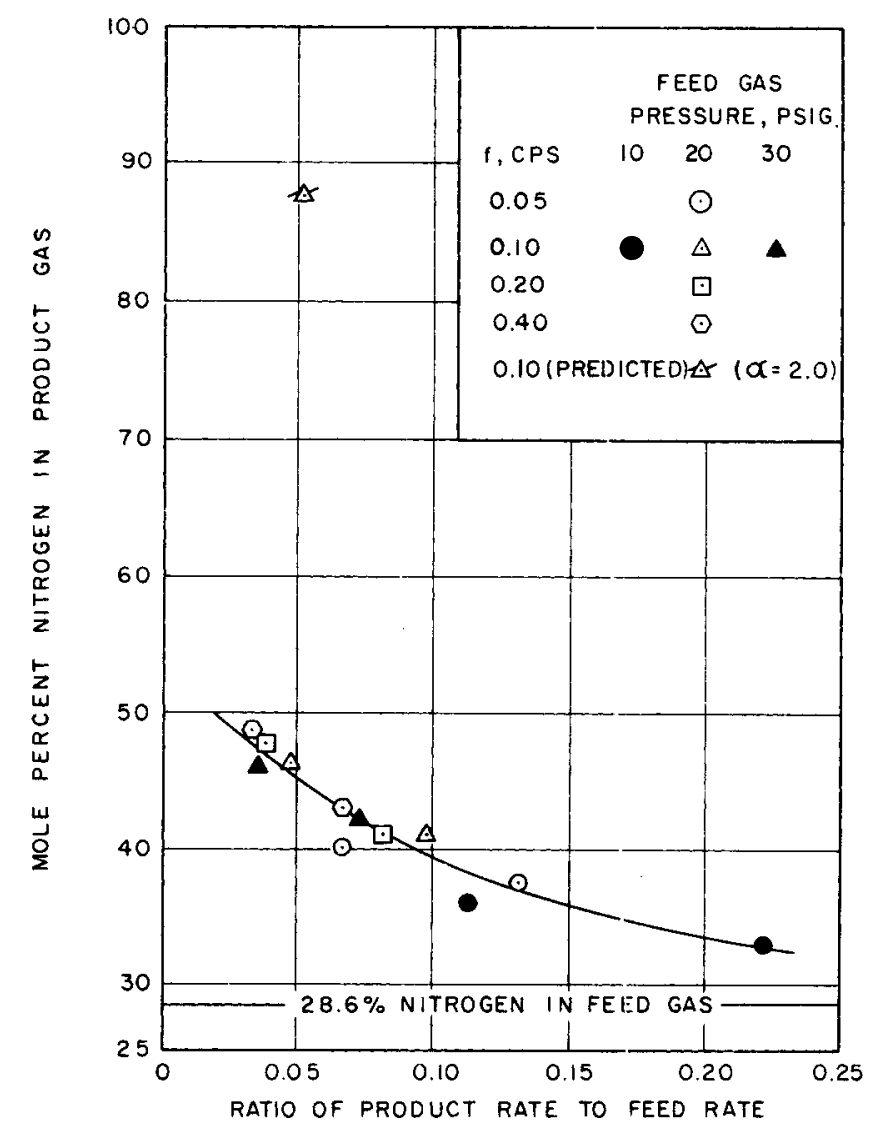

Fig. 11. Product gas compositions for various flow conditions ot - 77 ${ }^{\circ} \mathrm{C}$. (42-60 mesh particles of Type 5A Molecular Sieve). 


\section{SUMMARY AND CONCLUSIONS}

The effects of the process variables were examined over the following ranges: 10 to $30 \mathrm{lb} . / \mathrm{sq} . \mathrm{in}$. gauge feed gas pressure, 0.05 to 0.4 cycles/sec. cycling frequency, and 0.5 to $2.0 \mathrm{std}$. cu.ft./hr. product gas flow rate. The research was primarily conducted at a process temperature of $24^{\circ} \mathrm{C}$., but the effectiveness of cyclic operation at $0^{\circ}$ and $-77^{\circ} \mathrm{C}$. was also evaluated. Experimentally, the effects of the process variables were confounded with the effect of the unavoidably variable permeability of the packed bed. The 42-60 mesh particles of molecular sieve provided a measured permeability which ranged from 5 to 35 darcys near the feed end of the column. The lower permeability levels inhibited the degree of gas separation at the higher cycling frequencies. The combination of high gas flow resistance and rapid pressure cycling produced severely attenuated pressure waves, and correspondingly diminished nitrogen enrichments for the periodic process.

For most experiments the degree of gas separation was found to correlate with the ratio of the product gas rate to the feed gas rate, independent of the bed permeability, cycling frequency, or product gas flow rate over the studied ranges. At a fixed value of the product cut, greater nitrogen enrichment was achieved at a $20-\mathrm{lb} . / \mathrm{sq}$.in. gauge feed gas pressure than at a 10 -lb./sq.in. gauge feed gas pressure; further increase in the feed gas pressure produced only slight enhancement of the degree of gas separation. The observed advantage of feed gas pressures in excess of $20 \mathrm{lb} . / \mathrm{sq} . \mathrm{in}$. gauge was the significantly greater flow capacity which resulted. Similarly, more rapidly cyclic process operation increased the column flow capacity but not the degree of separation at equivalent values of the product cut. Thus elevated values of the bed permeability ( 5 to 35 darcys), feed gas pressure ( 10 to $40 \mathrm{lb} . / \mathrm{sq}$.in. gauge), and cycling frequency $(0.05$ to 0.4 cycles $/ \mathrm{sec}$.) within the designated ranges increased the column flow capacity without decreasing the nitrogen enrichment or percent recovery in the product gas. Although values of bed permeability and cycling frequency above 35 darcys and 0.4 cycles/sec., respectively, produced even greater flow capacity for the periodic process, the associated degrees of gas separation were diminished for comparable product cuts. The results summarized above were primarily obtained for process operation at $24^{\circ} \mathrm{C}$. but were also substantiated at $0^{\circ}$ and $-77^{\circ} \mathrm{C}$.

Operation of the periodic process at $0^{\circ} \mathrm{C}$. provided negligible contrast to operation at $24^{\circ} \mathrm{C}$; ; however, further reduction of the process temperature to $-77^{\circ} \mathrm{C}$. severely inhibited both the degree of gas separation and the flow capacity for the process. In addition the measured feed gas flow rate and product gas composition at $-77^{\circ} \mathrm{C}$. were considerably below those predicted by the derived, adsorption equilibrium process model .The reduced effectiveness of the periodic process at $-77^{\circ} \mathrm{C}$. is attributed to the existence of diffusion rate-controlled adsorption at the low temperature.

The efficiency of the periodic separation process decreases after attrition and compacting of the particles reduce the permeability of the packed bed below approximately 15 darcys. The attrition and compacting of the bed occur more rapidly at higher values of feed gas pressure and cycling frequency.

The flow rate of gas through the packed bed was characterized by Darcy's law for the mathematical simulation of the process. Darcy's law appears to be applicable for compressible gas flow through a porous, adsorbent medium. Comparisons of the computed and experimental results at $24^{\circ} \mathrm{C}$. were made at corresponding values of the feed gas pressure, cycling frequency, and product gas flow rate extending over the established ranges. The calculated pressure response, feed gas flow rate, and product gas composition corresponded favorably to the related experimental measurements for the periodic process. The extensive comparisons of computed and experimental results presented no evidence that the periodic process at $24^{\circ} \mathrm{C}$. is anything but an adsorption equilibrium process.

The rapidly cyclic process produces significant nitrogen enrichment of the product gas stream. However, an inherent deficiency of the periodic process results because the increased nitrogen enrichment of a nitrogen-methane mixture must be attained at the expense of a lower product cut. Achievement of substantial recovery and enrichment of a component by rapidly cyclic processing would require sequential recompression and reprocessing of the exhaust or product gas streams in a series of cyclic adsorption units.

\section{NOTATION}

$A=$ cross-sectional area of the pipe, sq.cm.

C = constant to convert std. cu.ft./hr. to mg.-moles/ sec. $=7.8658 / V_{m}$ (mg.-moles $/$ sec.) $/$ std. cu.ft. $/$ hr.

$f \quad=$ cycling frequency, cycles/sec.

$k=$ Freundlich relationship, constant

$K=$ permeability of bed, darcys

$l=$ distance along the pipe, $\mathrm{cm} .(l=0$ at feed end, $l=L$ at product end)

$L=$ total length of the pipe, $\mathrm{cm}$.

$n=$ Freundlich relationship, constant

$N=$ milligram-moles of gas adsorbed per gram of molecular sieve

$p_{a}=$ reference pressure of 1 atm. (total pressure)

$p_{f}=$ feed gas pressure, total pressure, atm.

$p(l, t)=$ absolute pressure, total pressure, atm.

$P(X, \theta)=$ dimensionless total pressure variable $=$ $\left(p(X, \theta) / p_{a}\right)^{2}$

$q(l, t)=$ volumetric flow rate at $p(l, t)$ and $T$, cu.cm./ sec.

$q_{m}(l, t)=q_{a}(l, t) / V_{m}$, molar flow rate, mg.-moles/sec.

$Q=$ average gas flow rate, std. cu.ft. $/ \mathrm{hr}$.

$R \quad=$ ideal gas law constant $=0.082057$ atm., cu.cm./ (mg.) (mole) $\left({ }^{\circ} \mathrm{K}.\right)$

$t \quad=$ time, sec.

$T=$ temperature of molecular sieve bed, ${ }^{\circ} \mathrm{K}$.

$T_{a}=$ ambient reference temperature $=298^{\circ} \mathrm{K}$.

$V=$ volume of the product line connections upstream of the pressure regulator $=47.5 \mathrm{cu} . \mathrm{cm}$.

$V_{m}=$ molar volume of an ideal gas at $p_{a}$ and $T_{a}=$ $24.453 \mathrm{cu} . \mathrm{cm}$./mg.-mole

\section{LITERATURE CITED}

I. Cannon, M. R., Oil Gas J., 51, 268 (July 28, 1952).

2. Schrodt, V. N., Ind. Eng. Chem. Fundamentals, 4, 108 (1965).

3. Wilhelm, R. H., A. W. Rice, R. W. Rolke, and N. H. Sweed, ibid., 7, 337 (Aug. 1968).

4. Lederman, P. B., Ph.D. thesis, Univ. Michigan, Ann Arbor (1961).

5. Carnahan, B., H. A. Luther, and J. O. Wilkes, "Applied Numerical Methods," preliminary edition, Vol. II, Chap. 7, J. Wiley, New York ( 1964)

6. Mickley, H. S., T. K. Sherwood, and C. E. Reed, "Applied Mathematics in Chemical Engineering," 2nd edit., Chap. 10 McGraw Hill, New York (1957).

7. Turnock, P. H., Ph.D. thesis, Univ. Michigan, Ann Arbor (1968).

8. Habgood, H. W., Can. J. Chem., 36, 1384 (1958).

Monuscript received April 24, 1969; revision received January 27, 1970; paper accepted January 30, 1970. 